\section{Electroanalytical Techniques for the Determination of Sulphite Preservative: An Editorial}

\section{Aurelia Magdalena Pisoschi}

University of Agronomic Sciences and Veterinary Medicine of Bucharest, Romania

"Corresponding author: Aurelia Magdalena Pisoschi, University of Agronomic Sciences and Veterinary Medicine of Bucharest, Faculty of Veterinary Medicine, Bucharest, Romania, E-mail: aureliamagdalenapisoschi@yahoo.ro

Received date: October 01, 2014, Accepted date: October 04, 2014, Published date: October 13, 2014

Copyright: (C) 2014 Pisoschi AM. This is an open-access article distributed under the terms of the Creative Commons Attribution License, which permits unrestricted use, distribution, and reproduction in any medium, provided the original author and source are credited.

\section{Editorial}

Sulphite, a commonly used preservative in foods and drinks is known for its reducing properties, as it can undergo oxidation to sulphate. Just as in the case of ascorbate, sulphite takes part in the antioxidant defence system that hinders the oxidative decay of food and drink components [1-8]. Sulfites, in their different forms, are present in: processed meats, wines, beer and cider, soft drinks and fruit juices, jams and jellies, dried and pickled fruits, shell fish, as well as processed food products for which protection against rancidity is required [1]. It has been stipulated that the antibrowning activity of sulfite involves direct inhibition of polyphenol oxidase or reduction of quinone derivatives (formed by the oxidation of phenolics) to 1,2dihydroxybenzene (catechol) derivatives [1].

Sulfur dioxide proved a promoter of the inflammation of the airways by neutrophil activation and is also involved in bronchoconstriction and worsening of the asthma pathology $[9,10]$. The adverse effects of sulphite may also include dermatitis, urticaria, flushing, hypotension, abdominal pain and diarrhea, or anaphylactic reactions [11], that is why its incorporation doses in the abovementioned foodstuffs are rigorously reglemented by Codex Alimentarius [12].

Its reductive power and inherent electroactivity enables its determination through various electrochemical techniques, namely voltammetry, amperometry, potentiometry.

During the investigation of sulphite electrochemical behavior at the surface of a graphite electrode in alkaline solution, it has been assessed that sulphite oxidation is an irreversibile process [13].

$$
2 \mathrm{SO}_{3}{ }^{2-}+\mathrm{O}_{2} \rightarrow 2 \mathrm{SO}_{4}{ }^{2-}
$$

Two possible mechanisms have been proposed [14-16] with respect to sulphite oxidation to sulphate - the redox process that generates the analytical signal, namely the anodic oxidation peak:

- sulphite anion is oxidized to sulphate in two successive steps, each implying one electron transfer, as follows [14]:

$$
\begin{aligned}
& \mathrm{SO}_{3}{ }^{2-} \rightarrow \mathrm{SO}_{3}{ }^{--}+\mathrm{e}^{-} \\
& \mathrm{SO}_{3}{ }^{\cdot-}+2 \mathrm{OH}^{-} \rightarrow \mathrm{SO}_{4}{ }^{2-}+\mathrm{H}_{2} \mathrm{O}+\mathrm{e}^{-}
\end{aligned}
$$

-sulphite anion is oxidized to sulphite radical in one single step characterized by one electron transfer, and then two sulphite radicals can interact giving dithionate $\mathrm{S}_{2} \mathrm{O}_{6}{ }^{2-}$, which consecutively disproportionates, resulting in sulphate and sulphite [14-16]. If the process takes place in alkaline media, it can be described by the equations below [14]:

$$
2 \mathrm{SO}_{3}^{--} \rightarrow \mathrm{S}_{2} \mathrm{O}_{6}{ }^{2-}
$$

$$
\mathrm{S}_{2} \mathrm{O}_{6}{ }^{2-}+2 \mathrm{OH}^{-} \rightarrow \mathrm{SO}_{3}{ }^{2-}+\mathrm{SO}_{4}{ }^{2-}+\mathrm{H}_{2} \mathrm{O}
$$

Voltammetry as electroanalytical technique involves recording of the current intensity, at an imposed potential variation. In the case of irreversible redox couples, the intensity of the cyclic voltammetric anodic oxidation peak can be directly correlated to the analyte concentration value.

Voltammograms corresponding to sulphite oxidation to sulphate in alkaline solution at a Pt stationary working electrode, show that the anodic oxidation peak becomes more pronounced and moves towards more positive potentials with increasing sweep rate that varied from 2 to $200 \mathrm{mV} / \mathrm{s}$ [14].

Sulphite electro-oxidation at a Pt disc rotating electrode has been reported to begin at around $380 \mathrm{mV}$ and to attain a limiting plateau at approximately $1000 \mathrm{mV}$ [14].

The much less figured cathodic peak (in comparison to the anodic one) noted at $-230 \mathrm{mV}$, has been assigned to the reduction of Pt oxides formed at the electrode surface $[14,17,18]$. The lack of a reduction peak corresponding to sulphite in both cases (stationary and rotating disc Pt electrodes) could suggest that either sulphite oxidation is irreversibile, or that it may be followed by a reaction which swiftly eliminates the product from the electrode surface [14].

The figure below illustrates a cyclic voltammogram obtained for sulphite with a potentiostat-galvanostat, at a Pt working electrode (Aurelia Magdalena Pisoschi, unpublished results).

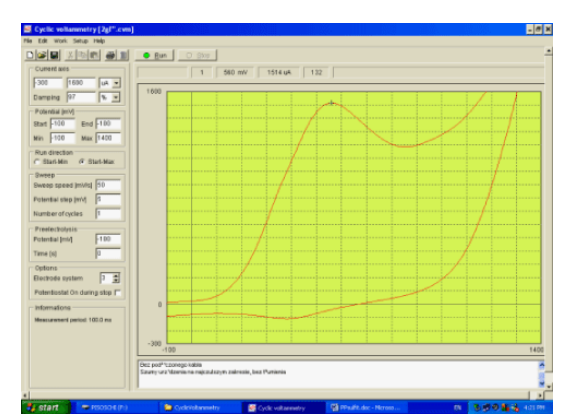

Figure 1: A cyclic voltammogram registered with the KSP potentiostat-galvanostat, at a bare Pt working electrode, for a $2 \mathrm{~g} / \mathrm{L}$ sulphite solution prepared in phosphate buffer $0.066 \mathrm{M}(\mathrm{pH} 7.0)$, in the presence of $0.1 \mathrm{M} \mathrm{KCl}$ as electrolyte (Aurelia Magdalena Pisoschi, unpublished results).

A novel cyclic voltammetric sensor for the simultaneous determination of $\mathrm{SO}_{3}{ }^{2-}$ and $\mathrm{NO}_{2}{ }^{-}$was proposed, relying on a glassy 
carbon electrode modified with graphene-chitosan and gold nanoparticles. The linear analytical range for sulphite corresponded to $5 \mu \mathrm{M}-0.41 \mathrm{mM}$, at $1 \mu \mathrm{M}$ detection limit. Moreover, the relative standard deviation value for sulphite was $1.1 \%$, the developed modified sensor being characterized by sensitivity, stability and reproducibility [19].

Amperometry is based on the recording of the current intensity at a fixed applied potential, in the absence or presence of a biorecognition element (incorporated in amperometric biosensors). The amperometric detection of sulphite in the presence of iodate and periodate, at a $\mathrm{Pt}$ electrode modified with multi-walled carbon nanotubes and Prussian blue nanoparticles, was possible at $600 \mathrm{mV}$ potential value for sulphite, and $320 \mathrm{mV}$ for iodate and periodate. The detection limits and catalytic rate constants were $4.70 \mu \mathrm{M}\left(5.24 \times 10^{7}\right.$ $\left.\mathrm{cm}^{3} \mathrm{~mol}^{-1} \mathrm{~s}^{-1}\right), 8.30 \mu \mathrm{M}\left(1.37 \times 10^{6} \mathrm{~cm}^{3} \mathrm{~mol}^{-1} \mathrm{~s}^{-1}\right)$ and $8.06 \mu \mathrm{M}$ $\left(0.34 \times 10^{6} \mathrm{~cm}^{3} \mathrm{~mol}^{-1} \mathrm{~s}^{-1}\right)$, for sulphite, iodate and periodate, respectively [20].

A sulfite biosensor was developed by immobilizing the enzyme sulfite oxidase at glassy carbon electrode coated with a mercury film. The electrochemical reduction of molecular oxygen at the surface of the working electrode is the reaction generating the analytical signal, at $-240 \mathrm{mV}$ working potential vs. $\mathrm{Ag} / \mathrm{AgCl}$ reference [21]. Essentially, the rate of oxygen consumption was proportional to the sulfite amount, and the peak current intensity decreased owing to molecular oxygen depletion in the sulphite oxidase catalyzed reaction:

$$
\mathrm{SO}_{3}{ }^{2-}+\mathrm{O}_{2}+\mathrm{H}_{2} \mathrm{O} \rightarrow \mathrm{SO}_{4}{ }^{2-}+\mathrm{H}_{2} \mathrm{O}_{2}
$$

The analytical linear response range was obtained between $2 \times 10^{-4}$ and $2.8 \times 10^{-3} \mathrm{M}$ sulfite [21].

Potentiometry relies on recording the potential difference that occurs as a result of an ionic species concentration (activity) change. The potential variation can be the outcome of a shift in the ratio between the oxidized and the reduced form of an indicating species that eventually transduces itself as a potential difference. For the assessment of sulphite (a reductant), the higher the concentration of the analysed species, the greater the concentration of the reduced form of the indicator, and therefore, the more enhanced the potential change. It has been determined that the use of naphtoquinone as indicator, results in good sensitivity towards sulphite [22].

It is important to stress out the role of the investigation and optimization of performant analytical methods, regarding food additives for which the content has to be rigorously controlled. Electrode modification may lead to enhanced analytical performances in terms of sensitivity and reproducibility; nevertheless, viable results can also be obtained with bare electrodes.

\section{References}

1. Isaac A, Livingstone C, Wain AJ, Compton RG, Davis J (2006) Electroanalytical methods for the determination of sulfite in food and beverages. TRAC 25: 589-598.

2. Thorpe SR, Baynes JW (2003) Maillard reaction products in tissue proteins: new products and new perspectives. Amino Acids 25: 275-281.
3. Martins SIFS, Jongen WMF, van Boekel MAJS (2000) A review of Maillard reaction in food and implication to kinetic modelling. Food Sci Technol 11: 364-373.

4. Manzocco L, Calligaris S, Mastrocola D, Nicoli MC, Lerici CR (2000) Review of nonenzymatic browning and antioxidant capacity in processed foods. Trends Food Sci Technol 11: 340- 346.

5. Lee KG, Shibamoto $\mathrm{T}$ (2002) Toxicology and antioxidant activities of nonenzymatic browning reaction products: review. Food Rev Int 18: 151-175.

6. Ashurst PR, Editor (1999) Production and packaging of non-carbonated fruit juices and fruit beverages, (2nd edn), Aspen Publishers, New York, USA.

7. Danilewicz JC (2003) Review of reaction mechanisms of oxygen and proposed intermediate reduction in wine: central role of iron and copper. Am J Enol Vitic 54: 73-85.

8. Pisoschi AM (2012) Food additives and ingredients-structures, properties, uses. Elisavaros Edition, Bucharest.

9. Vally H, Thompson PJ (2001) Role of sulfite additives in wine induced asthma: single dose and cumulative dose studies. Thorax 56: 763-769.

10. Lester MR (1995) Sulfite sensitivity: significance in human health. J Am Coll Nutr 14: 229-232.

11. Vally H, Misso NL, Madan V (2009) Clinical effects of sulphite additives. Clin Exp Allergy 39: 1643-1651.

12. GSFA Online Renseignements detailles sur le groupe d'additifs alimentaires pour sulfites.

13. Lu J, Dreisinger DB, Cooper CW (1999), Anodic oxidation of sulphite ions on graphite anodes in alkaline solution. J Appl Electrochem 29: 1161-1170.

14. Skavas E, Hemmingsen T (2007) Kinetics and mechanism of sulphite oxidation on a rotating platinum disc electrode in an alkaline solution. Electrochim Acta 52: 3510-3517.

15. Wiberg N (1985) Lehrbuch der anorganischen chemie. Walter de Gruyter, Berlin.

16. Senning A. (1972) Sulfur in organic chemistry. Marcel Dekker Inc, New York 2: 7.

17. Angerstein-Kozlowska H, Conway BE, Sharp WBA (1973) The real condition of electrochemically oxidized platinum surfaces: Part I. Resolution of component processes. Electroanal Chem Interf Electrochem 43: 9-36.

18. Tilak BV, Conway BE, Angerstein-Kozlowska H (1973) The real condition of oxidized pt electrodes: Part III. Kinetic theory of formation and reduction of surface oxides. Electroanal Chem Interf Electrochem 48: $1-23$.

19. Wang $\mathrm{X}, \mathrm{Li} \mathrm{H}, \mathrm{Wu} \mathrm{M}$, Ge S-L, Zhu Y (2013) Simultaneous electrochemical determination of sulphite and nitrite by a gold nanoparticle/graphene-chitosan modified electrode. Chin J Anal Chem 41: 1232-1237.

20. Adekunle AS, Arotiba OA, Mamba BB (2012) Electrochemical studies and sensing of iodate, periodate and sulphite ions at carbon nanotubes/ Prussian Blue films modified platinum electrode. Int J Electrochem Sci 7: 8503-8521.

21. Dinckaya E, Sezginturk MK, Akyilmaz E, Ertas FN (2007) Sulfite determination using sulfite oxidase biosensor based glassy carbon electrode coated with thin mercury film, Food Chem 101: 1540-1544.

22. Gracheva S, Livingstone C, Davis J (2004) Development of a disposable potentiometric sensor for the near patient testing of plasma thiol concentrations. Anal Chem 76: 3833-3836. 